\title{
Composição química e do conteúdo de energia do cariru (Talinum esculentum, Jacq.)
}

\author{
Luciana R. Trajano MANHÃES ${ }^{1}$, Mônica de Moraes MARQUES ${ }^{2}$, Armando Ubirajara O. SABAA-SRUR ${ }^{3}$
}

RESUMO

Estudos recentes têm relatado o estado pluricarencial da população dos estados da Região Norte do Brasil. Paradoxalmente nessa região encontra-se uma grande biodiversidade da flora com variadas frutas e hortaliças, ainda não tão conhecidas, mas que os pesquisadores acreditam ser altamente nutritivas. Entre elas, tem-se o cariru, planta herbácea da família Portulacea, hortaliça própria da região amazônica e de fácil cultivo. Amostras dessa verdura foram submetidas a determinaçōes analíticas a fim de obter maiores informaçôes sobre seu valor nutricional. A maior fração desse vegetal é a água (92,24\%), seguida de lipídeos $(3,04 \%)$, carboidratos $(2,94 \%)$, minerais totais $(1,71 \%)$ e de proteína $(0,07 \%)$, constituindo um alimento de reduzido valor calórico $(40 \mathrm{Kcal} / 100 \mathrm{~g})$. Tendo em vista os resultados encontrados na análise de minerais, essa folhosa pode ser considerada como excelente fonte de ferro, zinco e molibdênio, já que o consumo de $200 \mathrm{~g} / \mathrm{dia}$ desse alimento atenderia as necessidades diárias desses nutrientes. Chama-se atenção para os conteúdos de selênio e manganês, onde $100 \mathrm{~g}$ dessa biomassa fresca podem fornecer duas e três vezes, respectivamente, as quantidades recomendadas para adultos pelos órgãos internacionais de saúde, com as devidas precauçóes, já que excessos desses oligominerais podem causar danos à saúde. Sendo assim, recomenda-se a inclusão dessa folhosa no hábito alimentar brasileiro, por apresentar minerais em quantidades suficientes para minimizar o estado carencial de muitas pessoas, residentes na região Norte do país, exatamente onde é encontrada em abundância e com custo reduzido.

PalaVraS-CHAVE: Talinum esculentum, Jacq., Zinco, Ferro, Manganês, Selênio.

\section{Chemical composition and energy content of cariru (Talinum esculentum, Jacq.)}

\begin{abstract}
Recent studies have been related a food lacking state of population in states from north of Brazil. Paradoxically in this region a great biodiversity in the flora can be found with various fruits and vegetables, not very known so far, but researchers believe in their high nutritional values. One of them is Cariru, an herbaceous plant to Portulacea family, vegetable native from Amazon region and easy to grow. Sample of this vegetable was transformed in biomass and submitted to a quantitative analysis in order to have a lot of information about nutritional value. Analysis showed that the biggest amount was moisture ( $92.44 \%)$, followed by lipids (3.04\%), carbohydrates (2.94\%), total minerals $(1.71 \%)$ and protein $(0.07 \%)$, compound a reduced caloric food, 40 $\mathrm{kcal} / 100 \mathrm{~g}$. Analyzing the mineral results, cariru can be consider as an excellent iron, zinc and molybdenum source, that the consumption of 200 gin the vegetable/day would attend daily needs of these nutrients. This is very important to selenium and manganese contents, because $100 \mathrm{~g}$ fresh of biomass can supply 2 or 3 times, respectively, the RDI for adult. The excess of this oligominerals can be hazardous for human body. Therefore, the inclusion of this vegetable on a diet of Brazilian is recommended, because it presents enough minerals to minimize the food lacking state of people who lives in North of Brazil.
\end{abstract}

KEYWORDS: Iron, Zinc, Molybdenum, Manganese, Selenium.

\footnotetext{
1 Nutricionista, Mestre em Ciência e Tecnologia de Alimentos/ UFRRJ-IT-DTA. endereço CEP 23890-000. Seropédica - RJ. e-mail: lucianatrajano@gmail.com

2 Eng. de Alimentos, Doutoranda do Curso de Ciências de Alimentos da UFRJ - Prédio de IQ., $1^{0}$ andar, endereço CEP 21949-900. Rio de Janeiro - RJ. e-mail: paganimm@ig.com.br

3 Professor Adjunto do IN-DNBE-UFRJ, Prédio do CCS, Bloco J, $2^{\circ}$ Andar. endereço CEP 21949-900. Rio de Janeiro - RJ. e-mail: sabaasrur@yahoo.com.br
} 


\section{INTRODUÇÃO}

Em diversos estudos realizados no intuito de traçar uma avaliação nutricional da população residente nos estados do norte do Brasil tem sido observado um perfil pluricarencial das pessoas que moram naquela região (Alencar et al., 2000), caracterizado pela prevalência de desnutrição, sendo também freqüente as deficiências de vitaminas A, tiamina, riboflavina, niacina, além de alguns minerais como cálcio, ferro e zinco (Rocha et al., 1993). Paradoxalmente, vale ressaltar as inúmeras espécies da fauna e flora encontradas em todas as regiōes do norte, principalmente na floresta Amazônica, comprovando a grande biodiversidade dessa região. Além de frutas, consideradas nutritivas e encontradas em abundância, como cupuaçu (Theobroma grandiflorum Schum), bacuri (Plantonia insignis, Mart.), açaí (Euterpe oleracea, Mart.), taperebá (Spondias mombi, L.), algumas plantas também merecem destaque quanto a sua utilização no hábito alimentar da população nativa, como jambu (Spinlanthes oleracea, L.), vinagreira (Hibiscus sabdariffa, L.), cariru (Talinum esculentum, Jacq.), apesar de se ter pouca ou nenhuma informação sobre $\mathrm{o}$ valor nutricional desses vegetais.

Dados sobre a composição de alimentos são de extrema importância em saúde pública, pois é através deles que se torna possível a avaliação da ingestão alimentar de um indivíduo e conseqüentemente do seu estado nutricional (Frederico $e t$ al., 1984; Vannucchi et al., 1990). A inclusão desses dados nas diversas tabelas de composição de alimentos possibilita a adequação quantitativa da ingestão de nutrientes, podendo até contribuir para popularizar o uso de alguns alimentos de valor nutricional ainda desconhecido, como o cariru.

O cariru, também conhecido como caruru ou João-Gomes, é uma planta herbácea da família Portulacea. Própria da região amazônica e de fácil cultivo, não é tão exigente quanto a nutrientes para seu crescimento e as condiçôes edafoclimáticas da região são favoráveis ao seu cultivo (Pimentel, 1985). Tanto as folhas como as hastes e talos podem ser totalmente aproveitados na alimentação humana, em diversos pratos típicos da região, principalmente pela população amazônica das zonas rurais e da periferia das cidades.

Portanto, o presente trabalho teve por objetivo determinar a composição de macronutrientes e de minerais do cariru e incentivar a sua introdução no hábito alimentar do povo brasileiro, em especial a população da região norte do país.

\section{MATERIAL E MÉTODOS}

O cariru fresco foi comprado pela manhã na feira do "Ver-o-Peso" do município de Belém, estado do Pará, aproximadamente $10 \mathrm{~kg}$, e foi imediatamente transportado por via aérea sob refrigeração e transferido para o Laboratório de Determinações Físicas, Químicas e Físico-químicas do
Departamento de Tecnologia de Alimentos da Universidade Federal Rural do Rio de Janeiro.

Após a retirada da caixa de isopor, os maços do cariru foram desfeitos e selecionados, onde foram removidas as folhas e os talos com coloração parcial ou totalmente amareloclaro e textura tenra, além daqueles atacados por insetos. Já selecionados, foram imersos em água clorada contendo 150 ppm de cloro residual livre (CRL) e $\mathrm{pH}$ ajustado para sete com ácido clorídrico comercial. Após 15 minutos de imersão, os vegetais foram enxaguados em água corrente declorada, centrifugados a $2000 \mathrm{rpm}$ por dois minutos, acondicionados em sacos de polietileno de alta densidade, fechados a vácuo e armazenados a $-18^{\circ} \mathrm{C}$ até a realização das análises, que não ultrapassou 10 dias.

Antes das determinações, as amostras foram descongeladas e trituradas até completa homogeneização. As biomassas obtidas foram submetidas às determinaçóes analíticas, realizadas em triplicatas, para se conhecer a sua composição centesimal.

A umidade foi determinada por meio de secagem em estufa a $105^{\circ} \mathrm{C}$ até peso constante (IAL, 1985). A cinza (minerais totais) foi determinada pela incineração da amostra em mufla a $550^{\circ} \mathrm{C}$ (IAL, 1985). Para determinação dos minerais, as amostras foram calcinadas em mufla a $550^{\circ} \mathrm{C}$, por período mínimo de 2 horas e o resíduo obtido foi dissolvido em HCL $2 \mathrm{~mol}^{-1} \mathrm{l}^{-1}$, que em seguida foram analisadas por espectrometria de massa com plasma indutivamente acoplado no modo semi-quantitativo, utilizando o equipamento ELAN 6000 da Perkin Elmer-Sciex (AOAC, 1995). O nitrogênio total foi determinado pelo método de Micro-Kjeldahl (AOAC, 1995), sendo a proteína bruta calculada multiplicando-se o $\mathrm{N}$ por 6,25 (IAL, 1985). Os lipídeos foram determinados como extrato etéreo através de extração contínua pelo método de Soxlhet, utilizando clorofórmio como solvente (IAL, 1985). Os carboidratos totais foram determinados por diferença entre 100 e o somatório das frações protéicas, lipídicas, de umidade e de cinzas (IBGE, 1999).

Tabela 1 - Composição nutricional da biomassa de cariru in natura

\begin{tabular}{lcc}
\hline Determinações & $\mathbf{g} / \mathbf{1 0 0 g}$ amostra & $\mathbf{g} / \mathbf{1 0 0 g}$ amostra * \\
\hline Umidade & $92,24 \pm 2,181$ & 86,00 \\
Cinzas (Minerais totais) & $1,71 \pm 0,010$ & 2,10 \\
Lipídeos & $3,04 \pm 0,012$ & 0,80 \\
Carboidratos totais & $2,94 \pm 0,011$ & 7,40 \\
Proteínas (N x 6,25) & $0,07 \pm 0,001$ & 3,70 \\
\hline Valor calórico total $(\mathrm{kcal} / 100 \mathrm{~g})$ & 39,38 & 42,00 \\
\hline
\end{tabular}

* Fonte: ENDEF/ IBGE, 1999. 
Tabela 2 - Composição de minerais do cariru e suas recomendações para a alimentação humana.

\begin{tabular}{lcc}
\hline Mineral & g mineral $/ \mathbf{1 0 0 g}$ cariru & IDR $^{*}$ \\
\hline $\mathrm{Fe}$ & $9,4 \mathrm{mg}$ & $14 \mathrm{mg}$ \\
$\mathrm{Zn}$ & $7,1 \mathrm{mg}$ & $15 \mathrm{mg}$ \\
$\mathrm{Ca}$ & $100 \mathrm{mg}$ & $800 \mathrm{mg}$ \\
$\mathrm{Se}$ & $150 \mathrm{mcg}$ & $70 \mathrm{mcg}$ \\
$\mathrm{Mo}$ & $170 \mathrm{mcg}$ & $250 \mathrm{mcg}$ \\
$\mathrm{Al}$ & $5,1 \mathrm{mg}$ & - \\
$\mathrm{Mn}$ & $14,2 \mathrm{mg}$ & $5 \mathrm{mg}$ \\
$\mathrm{Na}$ & $68,9 \mathrm{mg}$ & - \\
$\mathrm{Cu}$ & $0,72 \mathrm{mg}$ & $3 \mathrm{mg}$ \\
\hline
\end{tabular}

* Fonte: Ingestão Diária Recomendada (IDR) para adultos, 1998.

No cálculo do Valor Calórico Total (VET) foram utilizados valores de conversão alimento/energia, sendo 4, 9 e 4 para carboidratos, lipídeos e proteínas, respectivamente, e depois feito o somatório desses valores (Lehninger, 1986).

\section{RESULTADOS E DISCUSSÃO}

O cariru in natura contém elevado teor de água (92,24\%), valor próximo ao encontrado na tabela de composição de alimentos - Estudo Nacional de Despesa Familiar (ENDEF)IBGE (1999), que foi de 86\% (Tabela 1). Esse fato pode contribuir para reduzir o tempo de prateleira deste alimento quando armazenado a temperatura ambiente.

É importante informar que dietas à base de cariru devem ser complementadas por outros alimentos considerados boas fontes protéicas, uma vez que a proteína do cariru está presente em concentraçôes reduzidas $(0,07 \%)$ (Tabela 1$)$. Além disso, por ser uma proteína vegetal, o cariru não atende, em sua plenitude, a necessidade diária de um adulto, além de ser considerada de baixo valor biológico.

O valor de proteína encontrado nessa pesquisa difere em muito o relatado pela tabela do ENDEF/IBGE (1999), que foi de $3,70 \%$ (Tabela 1). Porém essa tabela não é clara quanto à metodologia utilizada para obtenção da amostra. Além disso, esse valor deve ser reavaliado, já que a maioria das proteínas oriunda de folhosos não possuem valores tão altos de proteína (TACO, 2007).

O presente estudo encontrou 3,04\% de lipídeos, valor bem diferente do que foi encontrado pelo ENDEF/IBGE (1999) de $0,8 \%$ (Tabela 1). Tal fato pode ser atribuído à diferença metodológica aplicada em ambos os trabalhos. Nesse estudo foi aplicado o método de extração de Soxlhet, que apresenta uma eficiência de $100 \%$ em relação à extração a fração lipídica em função dos procedimentos adotados. Provavelmente a metodologia usada para obtenção dos dados exarados na tabela do ENDEF/IBGE (1999) não tenha sido a mesma metodologia utilizada nessa pesquisa.
Embora esse estudo e a tabela do ENDEF/IBGE (1999) tenham obtido os valores de carboidratos por diferença, foi encontrada uma diferença significativa entre eles, variação que pode ser creditada aos teores dos demais constituintes da composição desse produto, tanto nessa pesquisa como na tabela do ENDEF/IBGE (1999). Nesse estudo, o valor encontrado foi de 2,94\%, enquanto que na do ENDEF/ IBGE foi de 7,40\% (Tabela 1), reflexo das determinaçōes, principalmente, de lipídeos e proteínas.

No entanto, chama a atenção o baixo valor calórico desse alimento, onde $100 \mathrm{~g}$ representa em torno de $40 \mathrm{kcal}$, valor próximo ao informado pela Tabela do ENDEF/IBGE (1999), de 42kcal/ 100g alimento (Tabela 1). Dessa forma, essa folhosa pode contribuir para dietas de controle de peso, com a vantagem de atender as necessidades diárias de alguns minerais.

Os resultados das determinaçôes de minerais (Tabela 2) sugerem que a ingestão de $200 \mathrm{~g}$ dessa folhosa atende as necessidades diárias de ferro, zinco e molibdênio, segundo à Ingestão Diária Recomendada (IDR) para adultos (MS, 1998), muito embora tenha que ser considerada a biodisponibilidade desses nutrientes, ou seja, a fração desse mineral que é aproveitada pelo organismo através da absorção em relação ao teor total consumido. Essa absorção está relacionada com a forma química que estes elementos se encontram nos alimentos (Franco, 1995). A biodisponibilidade de um elemento pode ser afetada negativamente pela presença de fitatos, compostos fenólicos, fibra, alguns minerais entre outros (Souza Queiroz \& Torres, 1995), possivelmente presentes no cariru, necessitando de pesquisas mais específicas a respeito.

Esses dados tornam-se muito importantes quando se relaciona a alta prevalência de deficiências de minerais e suas conseqüências à saúde. Por exemplo, a deficiência de ferro é um dos grandes problemas de saúde pública no Brasil (WHO, 1993) e considerada a responsável pela maior parte das anemias encontradas (Queiroz \& Torres, 2000). Já a deficiência de zinco pode acarretar retardo no crescimento e no desenvolvimento cognitivo motor de crianças, bem como hiperceratose e paraceratose na pele e esôfago, atrofia do timo e gônadas (Sandstead, 1994). O déficit de molibdênio pode ocasionar alteraçôes mentais e anormalidades no metabolismo de enxofre e purinas (Krause, 2002).

As necessidades diárias de cálcio de um indivíduo adulto não são atendidas com uma ingestão diária de $200 \mathrm{~g}$ da biomassa do cariru, sendo preciso uma ingestão de aproximadamente $800 \mathrm{~g} /$ dia dessa hortaliça para evitar um quadro de deficiência de cálcio e suas conseqüências em um indivíduo adulto normal.

Deve-se atentar à concentração de manganês que essa hortaliça contém. Cerca de $30 \mathrm{~g}$ de cariru são suficientes para 
atender as recomendações diárias para uma pessoa adulta. A riqueza desse mineral deve ser nutricionalmente considerada, muito embora ele seja absorvido no intestino delgado da mesma forma que o ferro, compete com esse mineral pelo mesmo sítio de absorção, dificultando o seu aproveitamento pelo organismo. Outro fato relevante sobre a ingestão excessiva de manganês é o seu possível acúmulo no fígado e no Sistema Nervoso Central, produzindo sintomas semelhantes aos da doença de Parkinson (Finley, 1994), por isso, o consumo deve ser moderado até que estudos toxicológicos estabeleçam limite de ingestão tolerável.

O teor de selênio nesse alimento também deve ser muito considerado, uma vez que $50 \mathrm{~g}$ dessa hortaliça já são suficientes para atender as necessidades de um adulto. Isso parece ser importante em função do poder antioxidante que esse mineral possui, além de participar de várias reaçôes enzimáticas no organismo. Porém, se ingerido em excesso pode causar vários danos à saúde, desde alteraçôes cutâneas e das unhas, cárie dental a anormalidades neurológicas (Alvarenga, 2002).

Considerando o conteúdo de nutrientes dessa folhosa, este trabalho conclui que seria interessante o incentivo da sua inclusão na alimentação dos brasileiros residentes na região norte do país, pois apresentam alguns minerais em quantidades suficientes para melhorar o estado nutricional de centenas de pessoas, especialmente crianças e adolescentes. Exatamente nessa região, essa folhosa é encontrada com abundância, o que permiti se obter sempre alimentos frescos e de boa qualidade, além de baixo custo.

\section{REFERÊNCIA BIBLIOGRÁFICA}

Alencar, F.H., Yuyama, L.K.O., Nagahama, D. 2000. Estudo antropométrico da população infantil da calha do rio Negro, Amazonas, Brasil. 111 - Parque Nacional do Jaú. Acta Amazônica, 30(4): 665-669.

Alvarenga, R.M. Palavra de médico. Tudo o que você deve saber sobre as novas Fontes da Juventude. Disponível em: http:// palavrademedico.cjb.net/. Acesso em: 26/08/ 2002.

Association of Official Analytical Chemists (AOAC), 1995. Official Methods of Analysis. $12^{\circ} \mathrm{ed}$., Washington D.C. 1140pp.

Finley, J.W. 1994 Sex affects manganese absorption and retenhon by humans from a diet adequate in manganese. Am. J. Clin. Nutr., 60: 949.

Franco, G. 1995. Tabela de Composição de Alimentos. $9^{\circ} \mathrm{ed}$. Atheneu, Rio de Janeiro. 307pp.
Ministério da Saúde - MS. 1998. Ingestão Diária Recomendada (IDR) para adultos, Portaria 33, de 13 de Janeiro de 1998, da Secretaria de Vigilância Sanitária, do Ministério da Saúde.

Frederico, N.T., Marchini, J.S., Dutra de Oliveira, J.E. 1984. Alimentação e avaliação do estado nutricional de trabalhadores migrantes safristas na região de Ribeirão Preto, SP. Rev. Saúde Pub. 18: 375-381.

Instituto Brasileiro de Geografia e Estatística - IBGE. 1999. Estudo Nacional da Despesa Familiar - ENDEF. Tabelas de Composição de Alimentos/IBGE. $5^{\text {a }}$ ed.- Rio de Janeiro: IBGE.

Instituto Adolf Lutz - IAL. 1985. Normas Analíticas do Instituto Adolf Lutz. Métodos químicos e físicos para análise de alimentos. $3^{\circ} \mathrm{ed}$. São Paulo. v.1 533pp.

Krause, M.V.; Mahan, L.K. 2002 Alimentos, Nutrição \& Dietoterapia. 6aed. Ed. Roca. São Paulo. 981pp.

Lehninger, A.L. 1986 Princípios de Bioquimica. Sarvier: São Paulo. p. 211.

Pimentel, A. A. M. 1985. Pantoja - Olericultura no trópico úmido hortaliças na Amazônia. Editora da Universidade de São Paulo - USP. São Paulo. 191pp.

Souza Queiroz, S.; Torres, M.A.A. 1995. Anemia carencial ferropriva: aspectos fisiopatológicos e experiência com a utilização do leite fortificado com ferro. Ped. Mod., 31(Supl. 3): 441-455.

Souza Queiroz, S.; Torres, M.A.A. 2000. Anemia ferropriva na infância. J. Pediatria, 76(Supl. 3): 298-304.

Rocha, Y.R.; Yuyama, L.K.O.; Nascimento, P. 1993. Perfil nutricional de pré-escolares e escolares residentes em palmeiras do Javari, AM. Acta Amazônica, 23(1): 9-14.

Sandstead, H.H. 1994, Undrstanding zinc: rcent observations and interprettions. J. Lab. Clin. Med., 124: 322-327.

TACO/UNICAMP/NEPA - Tabela de Composição de Alimentos. Disponível em www.unicamp.br/nepa/taco/tabela. Acesso em: 08/11/2007.

Vannucchi, H.; Manezes, E.W.; Campana, A.O.; Lajolo, F.M. 1990. Aplicações das recomendações nutricionais adaptadas à população brasileira. Cad. Nutr., 2: 3-155.

World Health Organization (WHO). 1993. Use and interpretation of anthropometric indicators of nutritional status. Bull. World Health Organization, 64: 929-934.

Recebido em 08/09/2005

Aceito em 21/02/2008 